\title{
Pena de muerte, destierro o presidio: La suerte de los neogranadinos sediciosos y rebeldes en el siglo XIX
}

\author{
Death penalty, exile or confinement: The fate of the seditious and \\ rebellious neogranadins in the 19th century
}

\begin{abstract}
RESUMEN
Este ensayo describe la transformación de los delitos políticos y de los delitos de rebelión y sedición, en los Códigos Penales de 1837 y de 1873, como mecanismo de control a la oposición. Para ello se hace un repaso del contexto social, político y jurídico en el cual se expidieron indagando por las circunstancias que marcaron el establecimiento de estos delitos durante los dos cuartos intermedios del siglo XIX.
\end{abstract}

\section{PALABRAS CLAVE}

Derecho Penal, Estado, Pena.

\section{ABSTRACT}

This essay describes the transformation of political crimes and the crimes of rebellion and sedition in the penal codes of 1837 and 1873 as a mechanism of control to the opposition. To do so, a review of the social, political and legal context in which they were issued has been carried out investigating the circumstances that marked the establishment of these crimes during the two quarters of the nineteenth century.

\section{KEY WORDS}

Criminal law, State, Penalty. 


\section{INTRODUCCIÓN}

Ambición, inestabilidad e incertidumbre marcaron el parto de una República emergente que en sus primeros años afrontaría la necesidad de llenar el vacío de poder dejado por los españoles. La creación y consolidación del Estado republicano ocupó la agenda de los neogranadinos ahora emancipados de la madre España, el costo de ello, altísimo por supuesto, dejaría décadas enteras de luchas fratricidas que marcarían los inicio de la nueva Nación. Surgiría entonces, entre quienes fueron sucediéndose en el poder un interés especial por desincentivar aquellos actos que llevaban a la inestabilidad del Estado y por mantener al margen de la acción política a sus opositores, encontrando en el Derecho Penal herramientas ideales para hacerlo, una de ellas, la que hoy conocemos como delito político*

Cada uno de los estatutos penales adoptados durante el primer siglo de la República se destaca por contener dispositivos de control político a los disidentes, así, los primeros años de República granadina se caracterizaron por dar continuidad al régimen legal heredado de España y sería solo hasta 1837

Cuyos antecedentes se remontan a Roma, con los denofueron evolucionando hacia crimenes majestatis, hasta que, con el devenir de la Revolución Francesa, tomaron le forma que hoy conocemos, concebidos como actos mperante. Al respecto ver: Arboleda Vallejo, M. y otro (2007). Manual de Derecho Penal. Bogotá: Ed. Leyer. Sobre el derecho penal como mecanismo de control poHitco ver: Parada Garcia, G. E. (2012). Una historia del (1832-1842). ACHSC, 39(2), 101130 . que la Nueva Granada pudo contar con un Código Penal propio, aunque expedido so bre las bases del Derecho francés. Este Código, que inesperadamente logró conciliar las ideas liberales que inspiraron a las más influyentes clases sociales del naciente Estado, con la marcada religiosidad que mediab las relaciones de las clases populares, contaba con una particularidad respecto del tratamiento al delincuente político, pues le hacía susceptible de ser condenado a muerte (Pérez Felizzola, 2007, pp.9-42).

Tres décadas más tarde, se presentaría la oportunidad, para algunos, de consolidar las ideas liberales como horizonte civilizatorio, mientras para otros, el reto de recuperar e control del Gobierno y así cambiar el rumbo del país para salvarlo del ateísmo y la anarquía. Durante esos años la disputa política entre los diferentes grupos aspirantes a la dirección de la República, frecuentement desbordaba los precarios escenarios democráticos y les llevaba al uso de la violencia. Cobraría gran vigencia en ese momento una tercera vía, la Ley, que sería utilizada por los diferentes grupos como mecanismo pacificador que permitía mantener a distancia a la oposición política.

En medio de los ires y venires propios de la transición entre los gobiernos de turno, se fueron desarrollando dispositivos de control social para mantener a sus opositores alejados de cualquier actividad que pudiera desestabilizar el orden imperante. El presente ensayo ha sido preparado para exponer la transformación de los delitos políticos y esencialmente de los delitos de rebelión y se dieron a la tarea de dar forma a la estrucsedición, en tanto dispositivos de control a la tura sociopolítica de la infante República

oposición, en los Códigos Penales de 1837 y neogranadina.

de 1873 alrededor del contexto sociopolítico en el que se expidieron. Lo anterior para responder a la pregunta ¿qué circunstancias de la vida sociopolítica marcaron el establecimiento de los delitos de rebelión y sedición su configuración y sus penas en el ordenamiento jurídico penal granadino?

Para responder a la pregunta que ha sido formulada analizaremos las circunstancias sociales, políticas y jurídicas que llenaron de contenido a los delitos de sedición y rebelión durante los dos cuartos intermedios del siglo XIX, en dos momentos: primero, los antecedentes de su aparición en el Código Penal de 1837, configuración y castigos; y segundo, las particularidades que trajo consigo su configuración en el Código Penal de 1873 durante el Liberalismo Radical.

\section{Lel Código Penal de 1837}

os años de 1800 a 1830 marcaron la caída de la monarquía española y, consecuentemente, el nacimiento de la primera República granadina, que en sus primeros años se vio abocada principalmente a la tarea de llenar el espacio dejado por el imperio español. Así, las primeras filiaciones políticas granadinas surgirían en torno a debates sobre la organización del Estado. Civilistas, militaristas, bolivarianos, santanderistas, centralistas, federalistas, separatistas, unitarios, ministeriales, liberales, entre otros, conformaban el paisaje de los grupos de acción política que

La gran diversidad de posiciones respecto de la forma de gobierno constitucional que habría de adoptarse, giró en un primer momento alrededor de la necesidad de responder efectivamente a la reacción española que hasta la década de 1820 no abandonaba por completo la idea de perder el control sobre las colonias. A pesar de ello, la diversidad de opiniones y de actores que intentaban influir en la conformación del Estado, desbordó en a incapacidad para canalizar los conflictos por vías no violentas, de ahí los reiterados enfrentamientos entre diferentes facciones de la emergente clase dirigente neogranadina durante este periodo de tiempo.

Aquí, cobra especial interés y, si se quiere, marca una cierta tendencia por refundar la Nación cada vez que fuere necesario resolver las disputas sociopolíticas, el hecho de que la forma de canalizar el conflicto haya sido tradicionalmente el establecimiento de nuevos órdenes constitucionales. Así el primer antecedente de generación constitucional neogranadino lo encontramos en 1821, año en el que se consolida la integración de los territorios de Venezuela, Nueva Granada y Quito en la Gran Colombia, esto como resultado de la emergente Constitución de Cúcuta. Esta primera Constitución marcada por la victoria parcial de los centralistas sobre los federalistas, tendría una vigencia más bien corta (entre 1819 y 1930), pues las disputas 
tablecimiento de la Carta, por el contrario hombre de las leyes, se encargó de desarrose profundizaron y desbordaron en actos de llar las diversas tareas legislativas, cada una violencia, insubordinación, y sabotaje, como más urgente que la otra: no solamente era los derivados de la Convención de Ocaña que necesario concebir un nuevo Derecho susademás terminaría por disolver la Gran Co- tantivo (Civil, Penal, Comercial, de Policía) lombia (Ocampo López, 1990, pp.53-75).

El complejo panorama de inestabilidad institucional daría lugar al surgimiento de facciones políticas con diferencias cada vez más marcadas, destacan para la década de 1930 grupos como los ministeriales (conformados a partir de la unión de la llamada Sociedad Católica con los liberales moderados civilistas) o los liberales progresistas, grupos que no solo decoraron el entramado sociopolítico, sino que determinarían el rumbo de la inestable democracia local (Ocampo López, 1990).

En contravía de lo pretendido y pese a los intentos por configurar instituciones autónomas y estables, el Derecho vigente continuaba siendo el Derecho español. Sin embargo, los civilistas granadinos influenciados por las ideas de Jeremías Bentham, “...quien consideraba que el hombre es verdaderamente libre solamente dentro del Estado..." (Ocampo López, 1990, p.56). se dieron a la tarea de desarrollar sus propias instituciones jurídicas. "La transición fue vista como peligrosa, pues generó confusión sobre el Derecho vigente, pero la Constitución Política de 1832 evitó la vuelta al desorden, Llegó la ley, casi personificada en la figura del genera Santander, y fundamentada en un discurso secularizante. El cofundador de la República, que no en vano pasaría a la historia como $E$ que definiera los derechos, las obligaciones

las prohibiciones a los ciudadanos..." (Peñas Felizzola, 2007, p.14).

Como consecuencia de los debates que se sucedieron a la Constitución de 1832, una nueva legislación penal, neogranadina, verí la luz en 1837 durante el gobierno de José Ignacio Márquez (Nueva Granada. Congreso de la República, 1845). Se trataba de una legislación híbrida inspirada en el legalismo francés, pero dirigida a la exaltación de los principios religiosos que marcaban las relaciones en la base de la sociedad (Peñas Feeste, que pretendía sentar las bases para a estabilidad sociopolítica, tenía que introducir dispositivos para mantener controlada a la oposición, pues se consideraba que “...La síntesis hecha en la legislación penal de 1837 , entre ideas legalistas y de conservacatólico..." (Peñas Felizzola, 2007, p.19) era suficiente contenedor de las pretensiones políticas de los grupos de interés político que todo aquello que se alejara de las vías constitucionales para ejercer la política te"El nuevo Derecho Penal tenía que ser como el sujeto
que se pretendiá formar: racionall liberal y moral. Jere-
mias Bentham aportó las bases filosóficas de la codifica-
ción penal neogranadina, especialmente visibles en las ción penal neogranadina, especialmente visit."
definiciones de delito, delincuente y penas...". lizzola, 2007, pp.19-22)*. Un código como ción del orden social defendido por el culto nía que ser reprimido fuertemente*. Bien lo comprendería el Gobierno cuando en 1938 expidió un Decreto en el que se reglamenta a pena de muerte, ya prevista en Código, $y$ se amplía la imposición de este castigo para quienes fueran hallados culpables de delitos de carácter eminentemente político (Nueva Granada. Presidencia de la Republica, 1845)

Uno de los acontecimientos más paradigmáticos durante este periodo ocurrió en el transcurso de la llamada Guerra de los Supremos cuya crisis se ubica entre 1839 y $1942^{* *}$, en medio de la cual “...la ley pena sirvió al gobierno constitucional de Ignacio de Márquez para perseguir a sus rivales de la facción exaltada de los liberales..." (Parada Garcia, 2012, p.119). Una vez terminada la Guerra de los Supremos, el grupo de los llamados ministeriales (precursores de ideas centralistas) lograría reafirmarse en el poder al promulgar una nueva Constitución Politica, y con ella un modelo conservador de organización estatal, de marcado carácter

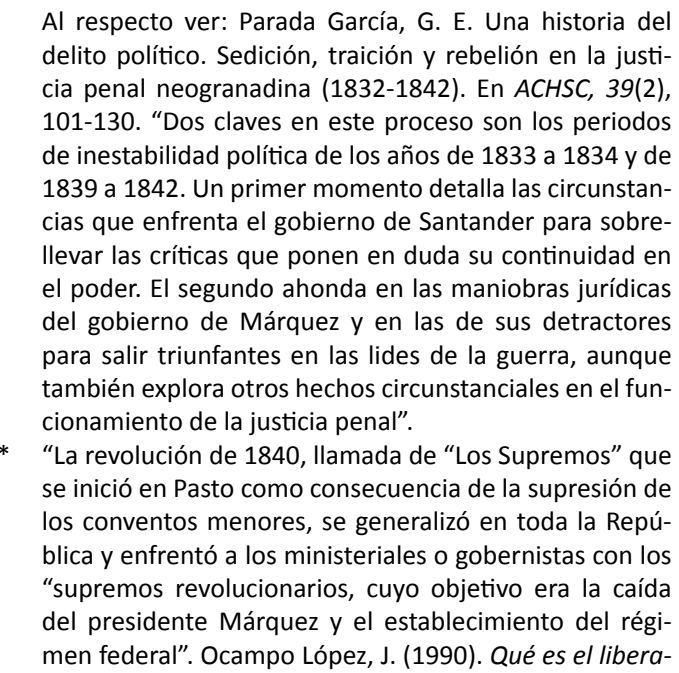
lismo colombiano. Bogotá: Ed. Plaza y Janés.

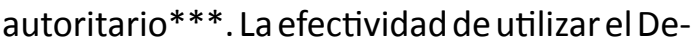
recho Penal como arma contra los opositores quedaría entonces demostrada, muy a pesar de los numerosos escandalos que llevaron a Márquez y a sus sucesores a reestructurar una y otra vez la administración de justicia".

Durante la vigencia del Código de 1837 rebeldes y sediciosos fueron juzgados con severidad, más aún cuando el Gobierno a expensas de la declaración de estado de sitio bajo la premisa de restablecer "el control social" ante la ebullición de los recurrentes conflictos que degeneraron en escenarios violentos durante los casi 40 años en que estuvo vigente este Estatuto Penal. Así lo dictaba la Ley del 27 de junio de 1937, al establecer como delitos los actos de rebelión y de sedición:

Artículo 232. Es rebelión el levantamiento ó insurrección de una porción más ó menos numerosa de súbditos de la república, que se alzan contra el gobierno supremo constitucional de la Nación, negándole la obediencia debida, ó procurando sustraerse de ella, ó haciéndole la guerra con las armas.

*** Después de numerosos combates $y$ tras las victorias de Buenavista y La Culebrera, se fortaleció el gobierno centralista de Márquez. Durante el mandato del general se afianzó más el centralismo en la Nueva en 1841, aún expresión fue la Constitución Política de 1843, de carácter centralista y autoritario. En 1845 triunfó en las elecciones el general Tomás Cipriano de Mosquera, quien (jernos apoyados por los ministeriales". Ocampo lópo1. (1990). Qué es el liberalismo colombiano. Bogotá: Ed. Plaza y Janes.

Afirmación que se ve reforzada al observar cómo, incluso antes de la abolición de la esclavitud, el 26 de mayo
de 1849 el Estado se vería obligado a eliminar la pena de muerte para los delitos políticos por vía de Ley. 
Artículo 233. Los que en la rebelión hayan Los textos transcritos permiten comprender procedido como autores principales son la configuración de los delitos de rebelión y traidores, serán declarados infames y su- de sedición hacia 1937, así como las penas frían la pena de muerte.

Artículo 236. Los demás comprendidos en a rebelión ó alzamiento, serán castigados con 4 a seis años de trabajos forzados.

Artículo 238. Es sedición el levantamiento ilegal i tumultuario de jentes, en número que pase por lo menos de veinte individuos con el objeto, no de sustraerse a la obediencia del Gobierno supremo de la Nación, sino de oponerse con armas sin ellas a la ejecución del alguna lei, acto constitucional, legal o de justicia, servicio lejitimo ó providencia de las autoridades, ó para atacar ó resistit violentamente a estas ó a sus ajentes. estos dos postuados centrales son esgrimidos en la redacción de los artículos en cuestión. Primero, obediencia debida al Gobierno Supremo de la Nación, su oposición semántica, es decir la desobediencia es lo que se castiga con penas que van desde la pena de muerte hasta la pena de trabajos forzados. Segundo, e grado de participación en la rebelión o la sedición -en cuanto actos de desobedienciasirvieron como rasero de la pena a imponer destacándose para este aspecto, por lo menos tres perfiles claramente definidos, el de autor principal, a ser castigado con pena de muerte para el caso de rebelión o pena de trabajos forzosos para la sedición; el de autor secundario, penado en los dos casos con pena de trabajos forzosos; $y$, específicamente para el delito de sedición, un tercer perfi criminal, el de cabeza de la misma, merecedor de la pena de muerte.

Artículo 239. Cuando se cometa el delito de sedición con armas, el que hace en ella cabeza será castigado con la pena de muerte, i los autores principales lo serán con la de doce a diez i seis años de trabajos forzados.

Artículo 240. Los demás sediciosos, qu no sean autores principales de la sedición [.] serán castigados según las circunstancias, con la pena de dos a diez años de trabajos forzados (Nueva Granada, Congreso de la República, 1845, p.188).
Código, llevarían a una serie de modificaciones que lo convirtieron en insostenible. La misma suerte la compartieron tanto la Constitución de 1843, como el Código Penal de 1837 , cuya vigencia comenzaría a deteriorarse con la llegada al poder de José $\mathrm{Hi}-$ ario López (de ideas liberales federalistas) en unas elecciones que fueron tachadas por los ministeriales como fraudulentas. $Y$ finatmente, tras la fundación de la Confederación Granadina en 1958 y posteriormente con el

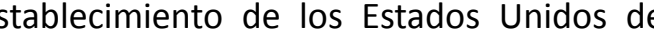
Colombia en 1961, los Estados de la Unión comenzaron a disponer de sus propios estatutos de justicia criminal, hasta que con la expedición de la Ley 112 de 1873 un nuevo Código Penal de carácter nacional vería la luz con él la legislación en materia penal quedaría nuevamente unificada.

carácter progresista del Código de 1873 es destacado por algunos juristas colombianos, no hay que olvidar la idealización que se ha hecho sobre el marco constitucional en el que se produjo esta nueva codificación la Constitución Política de 1863 que excluyó para todas las conductas punibles la pena de muerte, "...los liberales radicales hicieron especial protección de todos aquellos bienes jurídicos, que de forma directa permitieran a materialización del experimento liberal radical, como eran las garantías individuales, el ejercicio de los derechos políticos, orden público, autoridad pública, hacienda pública. libertades que hacían parte de las cartas de derechos de las cuatro Constituciones que rigieron en el Estado [de Santander] en distintos momentos, 1857, 1859, 1862, 1880
Constituciones que seguían línea por línea los dictados de la carta de derechos de la Constitución de los Estados Unidos de Colombia del año 1863" (Martínez Garnica et al., 2008, p.13).

Pese a lo anterior, los años de vigencia de la llamada Constitución de Rionegro no resultaron pacíficos, si bien sus años precedentes tampoco lo fueron, se cuentan por lo menos cinco guerras civiles de gran impacto entre los años 1851 y 1889. La primera de ellas en 1851 marcada por el levantamiento de sectores del Partido Conservador que se oponían a las reformas liberales, esencialmente en contra de la abolición de la esclavitud, que anunciaba el gobierno de José Hilario López; luego en 1854, como respuesta a la dictadura del general José María Melo cuyas medidas económicas beneficiaron a los comerciantes en desmedro de los intereses de los artesanos; otra en 1860, que enfrentó a Tomás Cipriano de Mosquera en insurrección contra el presidente conservador Mariano Ospina Rodríguez, guerra esta que derivaría en el triunfo de los federalistas y en la configuración de este tipo de gobierno en el país tras la Constitución de 1863; luego en 1876 cuando los conservadores estallan en contra de las reformas radicales promovidas por los dirigentes liberales, de la cual, los rebeldes conservadores terminarían vencidos; y una última en 1885 , como respuesta de los liberales radicales al movimiento de la regeneración que, ya en el gobierno, comenzaba promover la supresión de los dictados liberales (Ocampo López, 1990, pp.97-101). 
Así las cosas, la aparición del nuevo Estatuto Pese a lo anterior, 47 artículos del Código de Penal tras la sanción de la Ley 112 de 1973, 1873 desarrollarían el delito político, organien medio de la victoria de los liberales radi- zándolos como delitos contra el orden públicales (federalistas) que hablanlogado derro- co enlistados en el artículo 177 "Son deltos car al presidente Mariano Ospina Rodríguez contra el órden público: la traición a las insy restablecer su control sobre el Estado y sus tituciones; la rebelión; la sedición; el motín i la asonada". Llama la atención el hecho de derado por Rafal penas bien podrían no corresponderrotado en el campo de batalla se proyec- derido carácter humanista prueba de ello es la severidad de las meditaban como una fuerza política capaz de asu- das adoptadas que castigaban hasta con mir el control de la Nación como en efecto pena máxima establecida en el Código a los lo lograron en la década siguiente. El nuevo estatuto de persecución penal reflejaba de recurrente referencia a la pena de destierro alguna manera dos situaciones contrarias, como medida paliativa utilizada en contra de de una parte irrumpía en el escenario socio- rebeldes y sediciosos. Los textos originales político como materialización del romanti- son los siguientes:

cismo humanista que los liberales radicales añoraban, por otra parte, no dejaba de ser herramienta para enfrentar el contexto de rivalidad que para este momento ya asumía un cariz crónico.

Con la Ley 112 quedaría confirmada la supresión de la pena de muerte para toda clase de delitos, de igual forma es destacable la atenuación de las penas de presidio y de expulsión, las cuales no podían ser superiores a diez años. Mario Aguilera advierte sobre el carácter que, tras el establecimiento de la Constitución de Rionegro, iría tomando la política de Estado en materia criminal, así: "Luego, en la antesala de la Convención de Rionegro que expidió la Constitución de 1863 , y como un acto de olvido previo a esa "gran Convención", se desocuparon las cárceles del país al otorgarse la amnistía y el indulto general" (Aguilera, 2001) Articulo 183. Los demás comprendidos en la rebelión o alzamiento serán castigados con cuatro o doce meses de prisión.
Artículo 184. Es sedición el levantamiento ilegal i tumultuario de jentes, en número que pase por lo menos de veinte individuos, con el objeto de sustraers de la obediencia al gobierno supremo $\mathrm{d}$ la Nación, sino de oponerse con armas o sin ellas a la ejecución del alguna lei, acto constitucional, legal o de justicia, servicio lejitimo o providencia de las autoridades, para atacar o resistir violentamente a éstas $\mathrm{o}$ a sus ajentes.

Artículo 185. Cuando se cometa el delito de sedición con armas, el que hace en ella cabeza, será castigado con la pena de seis años de prisión, i los autores principales lo serán con la de dos a seis años de prisión.

Artículo 186. Los demás sediciosos que no sean autores principales de la sedición [...] serán castigados, según las circunstancias, con la pena de uno a cuatro años de prisión (EstadosUnidos de Colombia, Congreso de la República).

Así las cosas, dos son los cambios sustanciaes que trajo este nuevo Código respecto de anterior. Por un lado, amplía el número de acciones consideradas como actos de rebeión; por el otro, y tal vez la más característica, la eliminación de la pena de muerte y su reemplazo por las penas de presidio y destiero. Pese a lo anterior, son pocos los cambios de la estructura semántica entre una legislación y otra, se mantiene la obediencia debida al Gobierno, cuya transgresión amerita a imposición de las penas establecidas. Así mismo, los grados de participación parecen calcados de una legislación a otra, pero se destaca el cambio de doctrina en lo atinente al establecimiento de las penas, así: para el de autor principal de la rebelión, se reemplaza la pena de muerte por la de expulsión y n caso de sedición se reemplazan los trabajos forzados por el presidio; para los autores secundarios, se establece la pena de prisión reemplazando de esta manera la de trabajos forzosos; $y$, específicamente para la cabeza del delito de sedición, se asigna la pena de expulsión para reemplazar la de muerte contenida en el antiguo Código.

En pleno gobierno de Manuel Murillo se expidió esta legislación, pero su mayor vitalidad solo se alcanzaría en el gobierno de Aquileo Parra, durante el que estallaría una nueva insurrección conservadora que esta vez tuvo alcance y repercusión nacional. Los orígenes de esta revuelta se remontan a 1976 tras la promoción de un proyecto de ley que pretendía suprimir la enseñanza religiosa en las escuelas, excusa perfecta que los conservadores aprovecharon para levantarse en contra del gobierno liberal que, a su parecer, se había mantenido ya mucho tiempo en el poder. Este nuevo intento por sustraer el poder a los liberales fracasó, sin embargo: ". ya bajo la presidencia de Trujillo, de 1878 a 1880, el Partido Liberal empezó a desmoronarse con la salida de los independientes encabezados por Rafael Núñez, antes ultra radical. Más moderados en sus principios, poco a poco vieron crecer sus influencias, tanto que 


\section{CONCLUSIONES}

Los primeros años de desarrollo del Derecho Penal en la naciente República neogranadina estuvieron marcados por una relación de dependencia frente al Derecho español, tan solo 18 años después de terminada la guerra de independencia el Estado independiente dictaría su propio Estatuto Jurídico Penal. Esta situación resulta bien relevante considerando que gran parte de las bases para estructurar el nuevo gobierno se concentraron en la expectativa que generaba la Ley, la cual se le atribuía una gran capacidad de realización de las libertades alcanzadas.

El agitado panorama que rodeó el surgimiento del Estado, se agravaba cada vez más ante la radicalización de los sectores sociales que afiliados a determinadas corrientes sociopolíticas recurrieron una y otra vez al uso de la violencia como forma para incidir en la definición de los rumbos del país. El Derecho Penal entraría entonces a mediar en la conflictividad política que se fraguaba entre las diferentes facciones políticas que se enfrentaban por el poder, al dotar al Estado de herramientas que, como los delitos políticos, permitieron marginar -hasta cierto puntolas disidencias políticas. Sin embargo, las más de 50 guerras civiles que se desarroIlarían a lo largo del siglo XIX parecen dejar en entredicho la capacidad del Derecho Penal para apaciguar por sí solo las diferencias ideológicas que se suscitaron.

\section{REFERENCIAS}

Aguilera, M. (2001). Amnistías e indultos, siglos XIX y XX. Revista Credencial, (137). Consultado 02-10-15, en: http://www.banrepcultural.org/node/32817

Arboleda Vallejo, M. y otro (2007). Manual de Derecho Penal. Bogotá: Ed. Leyer.

Estados Unidos de Colombia. Congreso de a República. Código Penal, Lei 112 de 1873. Consultado 01-10-15. En: www.bdigital.unal. edu.co/5716/

Hettner, A. (1976). Viajes por los Andes colombianos. Bogotá: Talleres Gráficos del Banco de la República. Consultado 03-10-15, en http://www.banrepcultural.org/blaavirtual/ historia/viaand/indice.htm

Martínez Garnica, A. et al. (2008). El sistema jurídico en el Estado de Santander 1857 1886, Tomo 1. Bucaramanga: UIS. Consultado 01-10-2015, en: http://cultural.uis.edu. co/files/T14.pdf. El texto entre corchetes no se encuentra en el texto original.

Nueva Granada. Congreso de la República (1845). 1837, Código Penal de la Nueva Granada, Recopilación de leyes de la Nueva Granada. Compilador Lino de Pombo. Bogotá Imprenta Zoilo Salaza.

Nueva Granada. Presidencia de la República (1845). Decreto que determina lo concerniente a la ejecución de la pena de muerte establecida en el Código Penal, 1 de junio de
1838, Bogotá, 1838, en: Recopilación de Le- Parada García, G. E. (2012). Una historia del yes de la Nueva Granada. Formada y publicada en cumplimiento de la Ley de 4 de mayo 1843 por comisión del Poder Ejecutivo. Comp. Lino de Pombo. Bogotá: Imprenta de Zoilo Salazar.

Ocampo López, J. (1990). Qué es el conservatismo colombiano. Bogotá: Ed. Plaza \& Janés, delito político. Sedición, traición y rebelión en la justicia penal neogranadina (18321842). ACHSC, 39(2), 101-130.

Peñas Felizzola, A. H. (2007). Utilitarismo y tradicionalismo en la legislación penal repuBogotá

Ocampo López, J. (1990). Qué es el Liberalismo colombiano. Bogotá: Ed. Plaza y Janés. 